\title{
Localization Strategies of the Czech Companies on the Basis of Industrial-logistics Parks in the Sverdlovsk Region
}

\author{
Andrey Plakhin ${ }^{1, *}$, Rudolf Kampf $^{2}$, Ekaterina Ogorodnikova ${ }^{1}$, and Alexandr Kokovikhin ${ }^{3}$ \\ ${ }^{1}$ Ural state university of economics, Management Department, 620144 Ekaterinburg, Russia \\ ${ }^{2}$ Institute of Technology and Business in České Budějovice, Faculty of Technology, 37001 České \\ Budějovice, Czech Republic \\ ${ }^{3}$ Ural state university of economics, Institute of Management and Informatics, 620144, Ekaterinburg, \\ Russia
}

\begin{abstract}
The Czech Republic is traditionally a strategic partner of the Sverdlovsk region, the foreign trade turnover in 2015 exceeded \$ 134 million. This circumstance makes it possible to formulate a scientific hypothesis on strengthening in the long term international economic relations between our countries and increasing the degree of mutual penetration of economic entities. One of the most probable scenarios can be assumed, on the one hand, to create joint ventures both in the Czech Republic and the Russian Federation, on the other, Czech companies will focus on the opportunities that modern industrial-logistics parks provide to localize their productions. Thus, the purpose of this study is to study the theoretical, methodological and applied aspects of the strategic location of Czech companies on the sites of industrial-logistics parks in the Sverdlovsk Region. The article analyses the potential for localization of Czech companies in the Sverdlovsk Region as a whole, identifies areas for possible strategic interaction across economic sectors, explores the parametric characteristics of the industrial-logistics parks in the Sverdlovsk region, presents their rating and assesses the level of competitiveness.
\end{abstract}

\section{Introduction}

Localization of foreign companies' production is one of the most urgent areas of the import substitution strategy, which ensures the exchange of technologies. Today in many strategic industries the share of import consumption is estimated at more than $80 \%$ that makes a potential threat for both national security and the competitiveness of the Russian economy as a whole [1-3]. Accordingly, the urgent task remains to find the optimal strategy for placing industries localized in the Sverdlovsk region.

\footnotetext{
${ }^{1}$ Corresponding author : apla@usue.ru
} 


\section{Analysis of the localization potential of the Czech Republic companies in the Sverdlovsk Region}

For several decades, the Czech Republic remains a foreign trade partner of the Sverdlovsk region, in 2015 the turnover exceeded 134 million dollars. In the structure of the Sverdlovsk region exports to the Czech Republic metals predominate and products made from them, import from the Czech Republic to the Sverdlovsk region is mainly composed of the high redistribution products: engineering products, pumps and electrical machines.

Among the key importers are the following enterprises: FGUP "Kombinat Elektrokhimpribor" (spare parts for gas cutting equipment), LLC "Unimatic" (machine tool equipment), OJSC "NPK Uralvagonzavod" (equipment for modernization), CJSC "The Ural Turbine Works" (components for the production of turbines), LLC "UMK Pumori" (auxiliary tools), LLC "Delcam-Ural" (metal cutting equipment, engineering).

Further in Fig. 1, the main indicators of foreign trade of the Sverdlovsk region and the Czech Republic in 2011-2015 are presented.

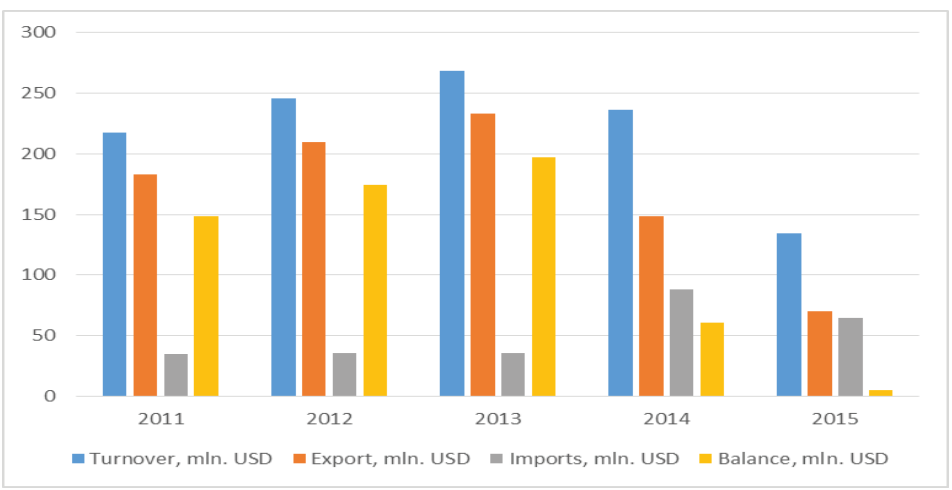

Fig. 1. Indicators of foreign trade of Sverdlovsk region with the Czech Republic in 2015. Source: [4]

In 2015, from the Sverdlovsk region to the Czech Republic metals and goods from them were mainly supplied (37\%), including ferrous metals and products made from them (20\%) (ferroalloys, semi-finished products, pipes, reduction of the supply volumes by more than 7 times), aluminum (14\%) (raw, profiles, sheets), copper (3\%) (reduction by 2 times). The share of machine-building products is $6 \%$, including mechanical equipment $(4 \%)$ (bearings), electrical equipment (2\%) (transformers), parts of railway locomotives and wagons. Shipments of the aircraft parts were actually ceased. Also, mineral products were supplied (1\%) (refined products), wood $(5 \%)$ (plywood). The share of the undeciphered group of goods is $(51 \%)$.

From the Czech Republic to the Sverdlovsk region machine-building products were mainly supplied (88\%), including mechanical equipment (69\%) (pumps, refrigeration equipment, processing centers for metal processing, machine tools, increase by 1.5 times in supplies of this group of products), electrical machines (11\%), railway equipment $(6 \%)$ (locomotives and their parts, significant growth), optical devices (6\%), shipments of the aircraft parts are stopped. The share of products from ferrous metals is $2 \%$ (significant decrease), chemical products $(2 \%)$ (plastics), mineral products $(1 \%)$ (products of the fuel distillation), other goods - $2 \%$ (ceramics).

Cooperation between the two regions is not limited to foreign trade operations. On the territory of the Sverdlovsk region joint projects are being implemented at various stages of implementation, that allows to talk about the localization of individual industries.

Different facts allow to draw a conclusion about the urgency of the development of a localization strategy for Czech producers in the Sverdlovsk Region. Localization of 
production leads to the costs reduction due to savings on transaction costs (reduction in costs for concluding and maintaining contracts for the supply and maintenance of the equipment), transportation costs and taxes [5]. Localization issues often concern existing institutional barriers, including problems that contribute to the difficulties in accessing resources, problems related to raising capital, using infrastructure facilities, et al. The solution of this problem is possible by placing companies in industrial-logistic parks.

\section{Characteristics of industrial-logistics parks in the Sverdlovsk Region}

A typical model of an industrial-logistic park allows to solve a whole range of tasks by attracting innovative enterprises, that leads to an increase in the number of jobs; supporting startups, developing high-tech enterprises; developing an environment where local and international firms can interact with knowledge creation centers; acting as innovative hubs, facilitating interactive learning and commercializing the results of scientific researches; developing local entrepreneurial potential, et al.

In general, the territory of the Sverdlovsk region includes sixteen industrial-logistic park projects, including the project of Special Economic Zone "Titanium Valley" [6].

Consider and study the available information for each park and then compare the industrial-logistic parks of the Sverdlovsk region on the main characteristics that determine the decision of the resident to choose a site.

In the Sverdlovsk region 16 industrial-logistic parks are declared. Most of the industriallogistic parks are created in the greenfield format (13 parks), the brownfield format is typical for the three parks of the Sverdlovsk region.

All industrial-logistic parks are significantly different in their key characteristics that determine the decision of a potential investor to choose a site for the construction of the facility [7, 12-15].

The following criteria have the most significant influence on the choice of a site for a certain industrial-logistic park:

- price of the land plot;

- provision of engineering infrastructure;

- distance from Ekaterinburg;

- status of the project (completion of creation the industrial-logistic park);

- the possibility of the flexible choice of the size and location of the land.

The characteristics of industrial-logistic parks in the Sverdlovsk region are represented according to the above criteria.

\subsection{Status of the project and provision of engineering infrastructure}

Only five parks out of the total number are operational or are at the final stage of implementation. These number includes the SEZ "Titanium Valley", HimPark Tagil, PROBUSINESS-PARK, "Berezovsky" and Uralmash. The other parks are in the process of elaboration of the concept for development and town-planning documentation.

Currently, the other industrial-logistic parks are in the following stages of project implementation:

- concept development: Muranitny;

- concepts are developed and park planning projects are developed or completed for the following parks: Magnitka, Novosverdlovsky, Uralsky, Novouralsky.

At the construction stage of the infrastructure are: Bogoslovsky, Titanium Valley. 
Many industrial-logistic parks will require a change in the category of land or the type of permitted use of the land. Thus, some land parcels refer to agricultural land or forest fund lands. For some the issues of transferring rights to land plots to management companies have not been resolved. Thus, even with intensive study, the solution of these problems will require considerable time. It takes from 1 to 2 years before the emergence of the real possibility of locating residents in the territory of these parks. These parks are Uralsky, Novosverdlovsky, Isetsky and Muranitny.

Depending on the stage of project implementation, the provision of industrial-logistic parks with engineering infrastructure is different. In the Berezovsky Industrial-logistic park, the power supply capacity is only $1 \mathrm{MW}$, which makes it possible to place a limited number of residents on its territory (only logistics facilities without refrigeration equipment and small manufacturing). Only "PRO-BUSINESS-PARK", Uralmash and HimPark Tagil are provided with sufficient resources. The rest of the parks are not provided with engineering infrastructure at all.

In addition to the availability of spare capacity and ready networks, an important factor is also the state of the engineering infrastructure and the costs of its maintenance [8].The infrastructure of the PRO-BUSINESS PARK was built in 2014-2015 and with a high degree of probability would not cause problems with its operation. Whereas the construction of engineering networks of Uralmash and HimPark Tagil was carried out in the $60-70$ s of the XX century. In this regard, their technical condition requires additional expertise and may necessitate substantial investment by management companies in their reconstruction. Meanwhile, for the purposes of this study this factor can be neglected. The amount of modernization costs will not significantly exceed the cost of building new networks in the planned greenfield parks. While the modernization of the infrastructure of these parks can be carried out in parallel with the operation of existing production facilities of the residents.

\subsection{Location next to the growing city and logistics accessibility}

The most demanded industrial-logistic parks are located in the area of developing settlements. In this regard, today a greater number of Industrial-logistic Parks are planned to be located near one of the largest transport and logistics hubs in the country, important industrial centers.

The higher competitiveness of industrial-logistic parks, created in dynamically developing cities, is caused by a combination of obvious reasons [9]. First of all, a dynamically developing settlement generates businesses that demand for industrial and commercial real estate. In addition, the population of a large or growing city has the necessary competencies and is able to meet the demand for skilled labor for new and existing industries.

In the Sverdlovsk region these centers may be primarily Ekaterinburg and satellite towns, Nizhny Tagil, Kamensk-Uralsky.

\subsection{Logistics accessibility}

Logistical accessibility is defined in terms of the standard costs for transport communication between different points.

Currently, the transport connection between the Sverdlovsk region and neighboring regions is carried out through the regional center (the city of Ekaterinburg). There are 6 federal highways, 7 main railway lines, and the largest international airport outside the two capitals. Taking into account this circumstance, Industrial-logistic parks located in the 
Ekaterinburg area along the Ekaterinburg ring road will have obvious transport accessibility.

At present, the geography of the Industrial-logistic Parks of the Sverdlovsk Region is the following: four industrial-logistic parks are located within the city of Ekaterinburg, six parks are located within $50 \mathrm{~km}$ from the city, four parks are located in the range from 51 to $150 \mathrm{~km}$, two industrial-logistic parks are located at the distance of more than $150 \mathrm{~km}$.

Special attention in terms of this criterion requires the industrial-logistic park "Bogoslovsky". This Industrial-logistic Park is located in the city of Krasnoturyinsk at a distance of $390-450 \mathrm{~km}$ from both Ekaterinburg and the regional centers of neighboring regions. The key task for the initiators of this project is obviously the identification of such residents, in the cost of which transport costs can not constitute a significant share.

\subsection{The presence of a branch specialization and anchor resident, around which a cluster can form}

Industry specialization is the division of labor in the material (industry, agriculture, transport, construction, et al.) and non-material (science, education, trade, medicine, et al.) industries. Anchor residents increase the attractiveness of the Industrial-logistic Park for potential investors, provide demand for scientific and engineering personnel, set work standards, create effective demand for technology companies and also become the basis for the emergence of spin-off companies. Thus, production and cooperation chains of enterprises can form around the anchor residents, that creates necessary conditions for the formation of viable clusters on the basis of an industrial-logistic park $[10,12,13]$. At the same time, it should be noted that specialization is not a strict restriction, on the territory of these parks there may be located production unrelated with the key residents industries. However, the availability of the possibility of forming a cluster makes it possible to generate ready-made investment proposals for companies in the target industries.

\section{Assessment of the industrial-logistics parks competitiveness in the Sverdlovsk Region}

In order to determine the competitiveness of industrial-logistic parks located in the Sverdlovsk region, their multi-attributive assessment was performed on the totality of the above criteria, which were significant for the residents.

The quantitative assessment of industrial-logistic parks for each criterion was carried out on the basis of the method of expert estimations. For this purpose, a survey of the business community representatives and employees of public authorities was conducted. Respondents were asked to assess the level of industrial-logistic parks attractiveness according to the certain parameters on a scale from 0 to 10 . The cumulative assessment by criterion was determined as the arithmetic average of the assessments of all experts divided by 10 . The sum of scores for each indicator shows the final coefficient of competitiveness.

A composite matrix was developed to visualize the findings, that allows in a visual form to group industrial-logistic parks of the Sverdlovsk Region in terms of their competitiveness. The horizontal axis shows the attractiveness for residents, expressed by the coefficients of competitiveness. The vertical axis reflects the stage of implementation: the status of the park, the degree of infrastructure readiness and the prospects for its creation in the near future, the time frame for creating the park (Fig. 2). 


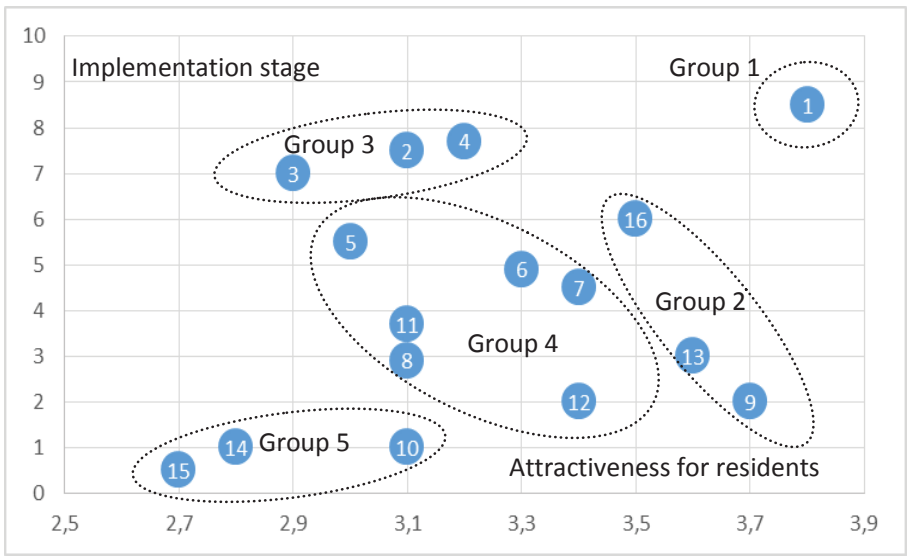

1 HimPark Tagil

2 Pro-Business-Park

3 Berezovsky

4 Uralmash

5 Bogoslovsky

6 Uralsky

7 Novosverdlovsky

8 Zarechny

9 Isetsky

10 Muranitny

11 Magnitka

12 Ekaterinburg

13 Sinarskij

14 Novouralsky

15 Ural

16 Titanium valley

Fig. 2. Grouping of industrial-logistic parks of the Sverdlovsk region by competitiveness. Source: compiled by the author

As a result, five groups of industrial-logistic parks in the Sverdlovsk region are identified.

Group 1. This group is characterized by the highest attractiveness for residents. Currently, this group includes only one industrial-logistic park, this is the operating park "HimPark Tagil". Chemical park is an industrial-logistic complex, consisting of chemical production, trade and service enterprises. The main objective of the project is the development of local business by attracting external investments and technologies of the park residents, creating favorable conditions for the development of chemical production in a single infrastructure complex.

Group 2 includes the second level parks in terms of attractiveness, which are characterized by favorable geographical position and subject to successful implementation, they will be provided with the necessary infrastructure in the near future. This group includes the Titanium Valley, Sinarskij, Isetsky. The most competitive platform among the parks being implemented is the Titanium Valley. This site also provides residents with extended benefits for federal and regional taxes as a special economic zone. Among the projected parks Isetskiy and Sinarskij parks occupy a favorable position. The specific sectoral focus of the economic zone is titanium and related production, which do not have competitors on the territory of Russia. Isetsky Park specializes on knowledge-intensive industries and is ready to place about 25 production sites with the creation of a cluster of one direction industries. Moreover, the infrastructure potential of the site will allow to expand the territory of the par in the long term. Specialization of the Sinarskij Park is engineering and metallurgy. These industrial-logistic parks have a small number of analogues due to the industry specialization and the availability of an anchor resident.

Group 3 includes existing industrial-logistic parks, on the territory of which it is possible to place production in the shortest possible time. Meanwhile, the parks of this group have significant drawbacks. In particular, the areas available for accommodation of residents are very small, the prices for plots are extremely high. This group includes industrial-logistic parks (in order of attractiveness reduction): Uralmash, "PRO-BUSINESS PARK", Berezovsky. These parks are located in the city of Ekaterinburg and therefore they have excellent logistical accessibility. Parks do not have a specific specialization, that is why there are many alternatives. Industrial-logistic Park Berezovsky occupies a weaker position among the existing parks. The park has good logistical accessibility, but it is 
poorly provided with engineering infrastructure, therefore it has a large number of analogues.

Group 4. The largest is the group of implemented and projected parks, whose competitive advantages are not obvious. It should be noted that all the parks of this group are at very early stages of creation. The dynamics of the implementation of most of the group's projects is purely declarative. Many of the parks included in this group are located in remote settlements from the regional center. They do not have an obvious and attractive anchor resident. Currently, the objective parameters of the group parks are also poorly estimated by investors. In this regard, the success of the projects to create industrial-logistic parks will largely depend on the ability to find a niche in the commercial and industrial real estate market. Implemented parks with average indexes are: Magnitka, Bogoslovsky, Uralsky, Novosverdlovsky, Zarechny, "Ekaterinburg". Industrial-logistic parks are located next to the growing populated areas, have good logistical accessibility, but they have quite a lot of alternatives.

Group 5. The last group includes projected parks with low attractiveness for the residents. These parks are: Novouralsky, Ural, Muranitny. Industrial-logistic parks have stopped on the development of concept and planning projects, the time constraints of infrastructure construction and commissioning of facilities are not known. Thus, it is possible to recommend implementation of the localization strategy for the companies of the Czech Republic in the industrial-logistic park of the first group - "HimPark Tagil".

According to the results of the study, it should be noted that the supply of industriallogistic parks in the Sverdlovsk region is limited [11]. In fact, it is possible to talk only about 4-5 really operating industrial-logistic parks.

Platforms in the regional center, undoubtedly, would be more attractive for attracting residents. These are industrial-logistic parks Uralmash, "PRO-BUSINESS PARK". However, according to experts, at present land plots in their territory are over and the offer is very limited. This circumstance determines the high price of land for investors and the inability to flexibly choose the configuration and location of the site for construction.

There is no substitute for such sites in the short term. Despite two or even three years of work on the problem of creating industrial-logistic parks in the Sverdlovsk Region, this process is far from being completed. All worthy alternatives to the existing industriallogistic parks are still at the initial stages of implementation.

In the medium term, subject to the successful implementation, the competition for HimPark Tagil may be formed by prospective industrial-logistic parks. First of all, it is necessary to focus on the sites in the Ekaterinburg area: Novosverdlovsky, Uralsky, Ekaterinburg. Also, the second-tier platforms may be interesting: Magnitka (Pervouralsk), Isetsky (Sredneuralsk). But in relation to these sites, HimPark Tagil also has a relative advantage in the form of a clear specialization in chemical production and the ability to locate objects with high hazard classes.

Thus, despite the large number of industrial-logistic parks declared on the territory of the Sverdlovsk region by the end of 2015, the creation of the industrial-logistic park "HimPark Tagil" is actual in the current conditions.

Undoubted competitive advantage of the industrial-logistic park "HimParkTagil" is also the presence of "anchor residents" in the form of the chemical industry enterprises: OJSC "Uralchimplast", OJSC "Ural Plant Of Polymer Materials", CJSC "UralMethanolGroup". This circumstance makes it possible to form a vertically integrated chemical cluster on the territory of this industrial-logistic park.

"HimPark Tagil" is potentially required and quite competitive in comparison with other parks, because of the following advantages:

- the possibility of placing objects of chemical industries, industries with a high level of danger; 
- despite chemical production, environmental safety remains;

- a relatively low price for renting land and premises;

- provision of engineering infrastructure with high capacities.

This paper is supported by the research project "From horse-drawn railway to intermodal transport" within Visegrad Fund.

\section{References}

1. I.V. Mukhanova, Russian State University for the Humanities Bulletin, Series: Economy, Management Law 3, 55-64 (2016)

2. E.V. Mezentseva, Proceedings of Southwest state University 3, 66, 102-111 (2016)

3. N.V. Zuboreva, Electronic Scientific Journal 13, 10-3, 47-51 (2016)

4. The Ministry of international and foreign economic relations of the Sverdlovsk region materials, The cooperation of the Sverdlovsk region with the Czech Republic

5. V.Yu. Markova, D.G. Shuvalova, Economic systems management: electronic scientific journal 58, 10, 61 (2013)

6. Investment portal of the Sverdlovsk region, Available online: http://invest.midural.ru/

7. A.E. Plakhin, A.B. Stavrova, T.V. Kochergina, Proceedings of the Baikal state University 26, 3, 400-410 (2016)

8. A.E. Plakhin, The manager 4, 50, 72-78 (2014)

9. E.S. Ogorodnikova, M.M. Sidorenko, Agri-food policy in Russia 11, 23, 97-99 (2013)

10. A.E. Plakhin, D.S. Mironov, ECONOMY, SOCIETY, PEOPLE: THEORY, METHODOLOGY, REALITY, Compilation of scientific publications: in 2 parts, 26-30 (The Ministry of Education and Science of the Russian Federation, Ural State University of Economics, Ekaterinburg, Russian Federation, 2015)

11. A.Yu. Kokovikhin, E.S. Ogorodnikova, D. Williams, A.Ye. Plakhin, Ekonomika regiona [Economy of Region] 13, 1, 80-92 (2017)

12. E.De Simone, M. D'Uva, Social Indicators Research 133, 3, 1031-1045 (2017)

13. I. Siskos, Van Wassenhove, N. Luk, Journal of Industrial Ecology 21, 4, 802-814 (2017)

14. S. Zheng, W. Sun; J. Wu, et al., Journal of Urban Economics 100, 80-103 (2017)

15. B.G. Hwang, L. Zhu; J.S.H. Tan, Journal of Cleaner Production 153, 1, 209-219 (2017) 